\title{
METABOLISMO DO NITROGÊNIO EM ALFAFA NODULADA SOB SUPRESSÃO E RESSUPRIMENTO DE FÓSFORO ${ }^{1}$
}

\author{
FERNANDO TEIXEIRA GOMES ${ }^{2}$, GILMARA DUARTE PEREIRA ${ }^{3}$, ARNALDO CHAER \\ BORGES $^{4}$, PAULO ROBERTO MOSQUIM ${ }^{5}$ E PAULO CEZAR REZENDE FONTES ${ }^{6}$
}

\author{
Departamento de Biologia Vegetal, Universidade Federal de Viçosa, Viçosa, MG. 36571.000, Brasil.
}

\begin{abstract}
RESUMO - Estudaram-se os efeitos da supressão e do ressuprimento de Pi sobre o metabolismo do nitrogênio, mediante a fixação biológica do nitrogênio atmosférico $\left(\mathrm{N}_{2}\right)$ e atividade da GS, Fd-GOGAT e NADH-GOGAT, em plantas de alfafa, cv. Flórida 77, inoculadas com Sinorhizobium meliloti, em diferentes estádios do desenvolvimento vegetativo (V3 e V4) e reprodutivo (R6 e R8). O ensaio foi conduzido em casa-de-vegetação e as plantas cultivadas em solução nutritiva. O período de supressão de Pi por dez dias reduziu os teores de Pi nas folhas e nos nódulos em todos os estádios do desenvolvimento, ao passo que nas raízes essa redução somente foi observada nos estádios vegetativos. Após o ressuprimento de Pi por igual período, ou seja, dez dias, foi observada a recuperação nos estádios R6 e R8 para folhas, V3 e V4 para raízes e V3 para os nódulos. A supressão de Pi reduziu significativamente os teores de aminoácidos totais nas folhas e nas raízes em todos os estádios do desenvolvimento, indicando que houve alteração no processo de fixação do $\mathrm{N}_{2}$. Após o ressuprimento, os teores de aminoácidos totais nas raízes, em todos os estádios do desenvolvimento, alcançaram valores similares àqueles das plantas do tratamento-controle, ao passo que nas folhas isso só ocorreu nos estádios vegetativos. A composição de aminoácidos na seiva do xilema não foi alterada em função da supressão e do ressuprimento de Pi. As atividades da GS e Fd-GOGAT, nos nódulos, foram reduzidas apenas nos estádios V3 e R8, enquanto com o ressuprimento não houve recuperação da Fd-GOGAT. Contudo, houve a recuperação da atividade da GS em R8. Nas folhas, a atividade da GS foi significativamente alterada em todos os estádios, enquanto a da Fd-GOGAT foi alterada somente em V3 e V4. Após o ressuprimento, não houve a recuperação da atividade da GS e Fd-GOGAT em V3. A NADH-GOGAT nas folhas e nos nódulos foi significativamente reduzida nos tratamentos de supressão de $\mathrm{Pi}$ em todos os estádios avaliados, não havendo recuperação após o ressuprimento. A NADH-GOGAT foi muito sensível à baixa disponibilidade de Pi. A supressão do Pi parece exercer controle na atividade dessas enzimas durante os diferentes estádios do desenvolvimento.
\end{abstract}

TERMOS ADICIONAIS PARA INDEXAÇÃO: Medicago sativa, supressão de fósforo, ressuprimento de fósforo, aminoácidos, GS/GOGAT.

ABREVIAÇÕES: Pi - Fosfato inorgânico, cv. - Cultivar, MF - Matéria fresca, GS - Sintetase da glutamina, Fd-GOGAT - Sintase do glutamato dependente de ferredoxina, NADH-GOGAT Sintase do glutamato dependente de NADH.

Recebido: 28/2/2001 - Aceito: 21/7/2001

1. Parte da tese apresentada pelo primeiro autor à Universidade Federal de Viçosa para obtenção do título de DS em Fisiologia Vegetal.

2. Biólogo, DS, Embrapa - Gado de Leite, Juiz de Fora, MG. E-mail: ftgomes@zipmail.com.br. Autor para correspondência.

3. Estagiária, Estudante de Agronomia - UFV, Viçosa, MG.

4. Professor Titular, PhD, Departamento de Microbiologia - UFV, Viçosa, MG.

5. Professor Titular, DS, Departamento de Biologia Vegetal - UFV, Viçosa, MG.

6. Professor Titular, PhD, Departamento de Fitotecnia - UFV, Viçosa, MG. 


\title{
NITROGEN METABOLISM IN ALFALFA NODULATED UNDER PHOSPHORUS SUPRESSION AND RESUPPLY
}

\begin{abstract}
Pi suppression and resupply effects were studied on nitrogen metabolism by means studied of evaluating on nitrogen biological fixation $\left(\mathrm{N}_{2}\right)$, GS, Fd-GOGAT and NADH-GOGAT activities in alfalfa cv. Florida 77 plants inoculated with Sinorhizobium meliloti in different vegetative (V3 and V4) and reproductive (R6 and R8) stages. The experiment was conducted in a greenhouse and the plants cultivated in nutritive solution. The Pi ten days suppression period decreased Pi levels in leaves and nodules in all growth stages, whereas in the roots this decrease was observed only in the vegetative stages. After Pi resupply to the nutritive solution during a similar period, ten days, it was observed Pi levels recovery in stages R6 and R8 for leaves, V3 and V4 for roots and V3 for nodules. Pi suppression significantly reduced total amino acids levels in leaves and roots in all growth stages, indicating that there was some alteration in the $\mathrm{N}_{2}$ fixation process. After Pi resupply to the nutritive solution, total amino acids levels in roots in all growth stages reached similar values when compared to the control. Whereas in leaves this only happened in the vegetative stages. Xylem sap aminoacids composition did not alter as a function of either the Pi suppression or resupply. GS and Fd-GOGAT in the nodules decreased only in stages V3 and R8, whereas with the resupply there was no Fd-GOGAT recovery. Nonetheless, there was recovery of GS activity in R8. In the leaves, GS activity was significantly altered in all stages, while FdGOGAT was altered only in V3 and V4. After the resupply there was no GS and Fd-GOGAT recovery in V3. The NADH-GOGAT in leaves and nodules was significantly reduced in tratments that suppressed Pi in all stages evaluated. Therefore, there was no recovery after resupply. NADH-GOGAT was quite sensible to low Pi availability. Pi suppression seems to exert control over those enzymes activities throughout all different growth stages.
\end{abstract}

ADITIONAL INDEX TERMS: Medicago sativa, phosphorus suppression, phosphorus resupply, aminoacids, GS/GOGAT

ABBREVIATIONS: Pi - inorganic phosphorus, cv. Cultivar, MF - Fresh weight, GS - Glutamine synthetase, Fd-GOGAT - Ferredoxin-dependent glutamate synthase, NADH-GOGAT - NADH-dependent glutamate synthase.

\section{INTRODUÇÃO}

Estudos sobre a influência do Pi na fixação simbiótica do nitrogênio atmosférico $\left(\mathrm{N}_{2}\right)$ têm recebido considerável atenção em leguminosas, em razão do alto requerimento desse elemento durante as fases de iniciação, crescimento e funcionamento dos nódulos radiculares (Al-Niemi et al., 1997). Observou-se que o Pi potencializa a fixação simbiótica do $\mathrm{N}_{2}$ por estimular o crescimento da planta hospedeira, além de afetar diretamente o crescimento do rizóbio e do nódulo (Chaudhary e Fujita, 1998). Em alfafa, a baixa disponibilidade de Pi nos solos reduz a produção de fotoassimilados, afetando negativamente a capacidade dos nódulos de manter a taxa de fixação de $\mathrm{N}_{2}$ (Vance et al., 1979).

A deficiência de Pi diminui a massa nodular (Israel, 1987) e a taxa fotossintética por unidade de área foliar (Qiu e Israel, 1992). A sacarose translocada pelo floema, das folhas para os nódulos, fornece a energia e os esqueletos carbônicos para a fixação do $\mathrm{N}_{2}$, assimilação do amônio e síntese "de novo" de purinas (Sá e Israel, 1995). Essas observações corroboram a hipótese de que a deficiência de Pi pode reduzir o suprimento 
de fotossintatos para os nódulos, resultando em um impacto negativo sobre a assimilação do nitrogênio em plantas de soja, em virtude da redução no suprimento de esqueletos carbônicos e energia para efetuar o processo assimilatório do $\mathrm{NH}_{4}{ }^{+}$(Sá e Israel, 1995).

A estimativa da fixação simbiótica do nitrogênio pode ser feita com base na concentração de $\mathrm{N}$-ureídeos e $\mathrm{N}$-aminoácidos na seiva do xilema de leguminosas noduladas. Pelos resultados obtidos em soja, constatou-se correlação positiva entre a abundância relativa de N-ureídico e a proporção de $\mathrm{N}_{2}$ fixado, medidos em todos os estádios de crescimento (Ohtake et al., 1995). Em soja submetida à supressão de Pi por sete dias, a porcentagem relativa de $\mathrm{N}$-ureídeo no exsudato do xilema foi reduzida, enquanto a concentração de aminoácidos totais aumentou em todos os estádios de desenvolvimento. Após o ressuprimento não foi observada nenhuma recuperação na porcentagem relativa de ureídeos (Silva, 1998).

Em plantas superiores, tanto a NADHGOGAT quanto a Fd-GOGAT têm ampla distribuição nos diferentes tecidos. A NADHGOGAT é considerada a forma mais importante nos nódulos de plantas de tremoço (Benny e Boland, 1977), feijão (Chen e Cullimore, 1988) e alfafa (Anderson et al., 1989). Em razão da presença de Fd-GOGAT na fração celular dos nódulos de soja, algumas funções fisiológicas dessa enzima estão relacionadas com a ciclagem do glutamato durante a assimilação do amônio proveniente da fixação do $\mathrm{N}_{2}$ (Suzuki et al., 1984).

Enquanto GS e NADH-GOGAT, em nódulos, são responsáveis pela assimilação primária do nitrogênio, GS e Fd-GOGAT foliares estão mais relacionadas à reassimilação dos íons $\mathrm{NH}_{4}^{+}$produzidos por outros processos fisiológicos. A atividade da Fd-GOGAT nos cloroplastos das folhas é induzida pela luz, estando relacionada com processos como a fotossíntese e a fotorrespiração (Lam et al., 1996). O amônio liberado pela fotorrespiração deve ser eficientemente refixado pela GS/Fd-GOGAT, o que possibilita grande economia de nitrogênio para as plantas (Hausler et al., 1994).
A atividade de GS, NADH-GOGAT e Fd-GOGAT, em plantas de soja sob supressão de Pi no início dos estádios vegetativos e reprodutivos, foi significativamente menor e não se recuperou com o ressuprimento de Pi. A supressão de Pi provocou redução nos teores de ureídeos, o que permitiu a inferência de que houve redução na atividade da nitrogenase e do sistema GS/GOGAT (Silva, 1998).

crescimento soja cujos nódulos apresentam principalmente ureídeos, a deficiência de $\mathrm{Pi}$ diminui a concentração de nitrogênio, tanto na parte aérea quanto nos nódulos; ao mesmo tempo, $\mathrm{o}$ ressuprimento resultou em aumento da nodulação, tanto em número quanto em massa nodular (Ribet e Drevon, 1995). Contudo, em alfafa, cujos nódulos apresentam crescimento indeterminado e o nitrogênio fixado simbioticamente é transportado principalmente na forma de amidas e aminoácidos, os efeitos do ressuprimento nas fases vegetativas e reprodutivas podem ser distintos dos da soja.

Assim, este estudo foi desenvolvido com o objetivo de investigar os efeitos da supressão e do ressuprimento de Pi em plantas de alfafa, cv. Flórida 77, inoculadas com Sinorhizobium meliloti, sobre o metabolismo do nitrogênio, avaliado pela fixação biológica do $\mathrm{N}_{2}$ e pela atividade da sintetase da glutamina e da sintase do glutamato, tanto no estádio vegetativo quanto no estádio reprodutivo da planta.

\section{MATERIAL E MÉTODOS}

Sementes de alfafa (Medicago sativa (L.), cv. Flórida 77) fornecidas pela Embrapa Gado de Leite, em Juiz de Fora, MG, foram previamente esterilizadas superficialmente por imersão em etanol $70 \%$ por 1 min e em peróxido de hidrogênio 6\% (v:v), por $5 \mathrm{~min}$, seguindo-se cinco lavagens em água destilada estéril (Vincent, 1970). A germinação das sementes foi realizada em areia lavada e esterilizada. Quando atingiram o estádio de desenvolvimento V2 (folha trifoliolada, completamente desenvolvida no nó acima do nó 
das folhas unifolioladas), as plântulas foram selecionadas quanto à uniformidade de tamanho e, em seguida, inoculadas com Sinorhizobium meliloti.

Após a inoculação, as plantas foram cultivadas em vasos de isopor com capacidade de $5,0 \mathrm{~L}$, revestidos internamente com sacos de polietileno contendo solução nutritiva de Hoagland e Arnon (1950), modificada, cuja composição é: K, 3,0; Ca, 3,0; Mg, 1,0; P, 0,14; S, 2,0 mM; B, 46,0; $\mathrm{Zn}, 1,5 ; \mathrm{Cu}, 0,3 ; \mathrm{Mo}, 0,6 ; \mathrm{Mn}, 18,0$; Fe-EDTA, $38,0 \mu \mathrm{M}$. O NH $\mathrm{NH}_{4} \mathrm{~N}, 0,1 ; \mathrm{NO}_{3}-\mathrm{N}, 0,6 \mathrm{mM}$ somente foram adicionados à solução nutritiva na primeira semana de crescimento, e o Co, $0,75 \mu \mathrm{M}$, somente nas três primeiras semanas. Os vasos receberam arejamento contínuo e o $\mathrm{pH}$ da solução nutritiva foi ajustado diariamente em $6,0 \pm 0,3$, mediante a adição de $\mathrm{HCl} 1,0 \mathrm{~N}$ ou $\mathrm{NaOH} 1,0 \mathrm{~N}$. As trocas de solução nutritiva foram efetuadas semanalmente durante os estádios vegetativos e no intervalo de três dias durante os estádios reprodutivos.

\section{Delineamento experimental}

Foram executados dois ensaios. $\mathrm{O}$ primeiro foi realizado para investigar os efeitos da supressão do Pi durante os estádios vegetativos V3 (folhas completamente desenvolvidas no $5^{\underline{0}}$ nó acima do nó das folhas unifolioladas) e V4 (folhas completamente desenvolvidas no $7^{\mathbf{0}}$ nó acima do nó das folhas unifolioladas) e reprodutivos R6 (um nó com uma flor aberta) e R8 (um a três nós com vagem verde). As plantas atingiram os estádios de desenvolvimento V3, aos 21 dias; V4, aos 36; R6, aos 82; e R8, aos 95 dias após o transplantio. Esse ensaio consistiu de dois tratamentos: a) controle, Pi durante todo o período experimental; e b) supressão do Pi por dez dias, quando as plantas atingiram os estádios V3, V4, R6 e R8. Após o período de supressão, as plantas foram coletadas e as análises efetuadas.

O segundo ensaio foi realizado para investigar os efeitos do ressuprimento de $\mathrm{Pi}$ durante os estádios V3, V4, R6 e R8. Esse ensaio também foi constituído de dois tratamentos: a) controle, Pi durante todo o período experimental e b) ressuprimento de Pi por dez dias após período de supressão também de dez dias, quando as plantas atingiram os estádios V3, V4, R6 e R8. Após o período de ressuprimento, as plantas foram coletadas e as análises efetuadas.

Foram utilizadas parcelas de duas plantas por vaso, num esquema fatorial constituído de dois tratamentos e quatro épocas de amostragem, com quatro repetições, dispostas num delineamento experimental inteiramente casualizado. Os dados foram submetidos à análise de variância, a $5 \%$ de significância pelo teste de Fischer (F) e análise de regressão. Utilizou-se nessas análises o programa SAS.

\section{Coleta da seiva do xilema e dosagem de aminoácidos}

Para a coleta da seiva do xilema, os caules das plantas foram secionados acima do nó cotiledonar e o material coletado foi imediatamente transferido para frascos de vidro mantidos em banho de gelo e posteriormente conservados a $15^{\circ} \mathrm{C}$.

A separação dos aminoácidos livres foi efetuada por meio de cromatografia líquida de alto desempenho, em coluna de fase reversa C 18 Superpac ODS - 2, após a derivação com oftaldialdeido (OFA) (Benson e Hare, 1975; Jarret et al. 1986).

Uma alíquota de $20 \mu \mathrm{L}$ da amostra foi adicionada a um tubo eppendorf contendo $60 \mu \mathrm{L}$ do reagente OFA. Após 2 minutos de derivação, 10 $\mu \mathrm{L}$ da mistura foram injetados no cromatógrafo. As concentrações de aminoácidos nas amostras foram determinadas pela área dos picos integrada, comparada aos picos de um padrão Sigma 18, com 15 aminoácidos protéicos, e de outro padrão com os aminoácidos asparagina (Asn), glutamina (Gln) e ácido $\gamma$-amino butírico (GABA), todos em concentração de $2,5 \mathrm{mM}$.

\section{Aminoácidos livres totais}

Os teores de aminoácidos totais foram determinados no segundo trifólio superior completamente expandido, a partir do ápice e em amostras de raízes finas localizadas nas 
extremidades do sistema radicular. Os aminoácidos totais foram determinados por meio de reação colorimétrica com ninhidrina, a partir de uma curva-padrão de glicina (Gly), glutamato (Glu), arginina (Arg) e fenilalanina (Phe), usando-se concentrações de até $0,1 \mu \mathrm{M}$ (Rena e Masciotti, 1976).

\section{Determinação dos teores de Pi}

Os teores de Pi foram determinados no terceiro trifólio superior, completamente expandido, a partir do ápice e em amostras de raízes finas e de nódulos, utilizando-se o método proposto por Smille e Krotkov (1960) e adaptado por Houge et al., (1970).

\section{Ensaios enzimáticos}

Para a determinação da atividade da GS e GOGAT, em todos os ensaios foi preparado o meio de extração (Hausler et al., 1994) modificado, com a seguinte composição: tampão TRIS-HCl 100 $\mathrm{mM}(\mathrm{pH} 7,8), \mathrm{MgSO}_{4} 2,5 \mathrm{mM}, \mathrm{KCl} 25,0 \mathrm{mM}$, DTT $1,0 \mathrm{mM}, \beta$-mercaptoetanol $1 \%(\mathrm{v} / \mathrm{v})$, EDTA 0,25 $\mathrm{mM}$, Triton X-100 0,5\%, glicerol 2,0\% (v/v). Foi utilizada uma relação de $5,0 \mathrm{~mL}$ de tampão de extração por grama de folhas ou nódulos, que foram macerados em almofariz com pistilos previamente resfriados. A temperatura de extração foi mantida próxima de $4^{\circ} \mathrm{C}$, utilizando-se banho de gelo. O homogenato, assim obtido, foi centrifugado a $15.000 \mathrm{~g}$, por $15 \mathrm{~min}$, a $4^{\circ} \mathrm{C}$. Alíquotas do sobrenadante foram imediatamente utilizadas para as avaliações da atividade enzimática.

\section{Sintetase da glutamina (GS; EC 6.3.1.2)}

A atividade da sintetase da glutamina foi determinada pela formação de $\gamma$-glutamilhidroximato e quantificada com cloreto férrico acidificado. $\mathrm{O}$ ensaio foi realizado segundo Rhodes et al. (1975), modificado por Tonin (1988) e Junghans e Mosquim (1995). A alíquota de 0,05 $\mathrm{mL}$ do extrato foi acrescentada à solução de ATP 6,25 mM, $\mathrm{MgSO}_{4}$ 45,0 mM, hidroxilamina- $\mathrm{HCl}$ $6,25 \mathrm{mM}$, glutamato $93,75 \mathrm{mM}$ e tampão TRIS
100,0 mM (pH 7,2), em volume final de 3,2 mL. O meio de reação foi incubado a $30^{\circ} \mathrm{C}$ em banhomaria e, após 20 min de incubação, foram retiradas alíquotas de 0,8 $\mathrm{mL}$, adicionando-se, a cada uma, $1,2 \mathrm{~mL}$ do reagente constituído por uma mistura de ácido tricloroacético $0,20 \mathrm{M} \mathrm{e} \mathrm{FeCl}_{3} 0,37 \mathrm{M}$, diluídos em $\mathrm{HCl} 0,67 \mathrm{~N}$. As proteínas foram removidas por centrifugação a $10.000 \mathrm{~g}$ por $5 \mathrm{~min}$. A absorvância no sobrenadante foi medida a $540 \mathrm{~nm}$. O branco foi constituído da mistura citada, mas sem o glutamato. Uma curva de calibração foi construída, usando-se $\gamma$-glutamil-hidroximato (GHA) como padrão, com concentrações de até 1,0 $\mu \mathrm{M}$.

\section{Sintase do glutamato dependente de ferredoxina (Fd-GOGAT; EC 1.4.7.1.)}

Para a determinação da atividade da FdGOGAT, foi utilizado, como substrato, o metilviologênio reduzido, em vez da ferredoxina (Hausler et al., 1994). Uma alíquota de $0,3 \mathrm{~mL}$ do extrato cru foi acrescentada a uma solução de glutamina $10,0 \mathrm{mM}$, 2-oxo-glutarato $10,0 \mathrm{mM}$, metil-viologênio $8,0 \mathrm{mM}$ e tampão fosfato 100,0 $\mathrm{mM}(\mathrm{pH} 7,5)$, em volume final de 1,5 mL. Após pré-incubação em banho-maria, a $30^{\circ} \mathrm{C}$ por $2 \mathrm{~min}$, a reação foi iniciada com a adição de $0,3 \mathrm{~mL}$ do agente redutor $\left(16,0 \mathrm{mg}\right.$ de $\mathrm{Na}_{2} \mathrm{~S}_{2} \mathrm{O}_{4}$ e $16,0 \mathrm{mg}$ de $\mathrm{NaHCO}_{3}$ em $1,0 \mathrm{~mL}$ de $\mathrm{H}_{2} \mathrm{O}$ ). A reação foi interrompida após $20 \mathrm{~min}$, mergulhando-se os tubos em banho-maria a $90^{\circ} \mathrm{C}$ por $2 \mathrm{~min}$. Os tubos de ensaio foram agitados vigorosamente para garantir a re-oxidação do metil-viologênio. O glutamato formado na reação foi separado da glutamina, por meio de cromatografia de troca iônica, passando-se a mistura numa coluna de Dowex-1 na forma de acetato (100-200 mesh), equilibrada com ácido acético $0,3 \mathrm{M}$. A glutamina foi lavada na coluna com $15 \mathrm{~mL}$ de água destilada e o glutamato foi eluído em $5,0 \mathrm{~mL}$ de ácido acético 0,3 M. O glutamato formado durante a reação foi quantificado usando-se ninhidrina. Uma alíquota de $1,0 \mathrm{~mL}$ do eluído foi misturada a 2,0 $\mathrm{mL}$ da solução de ninhidrina $(0,4 \mathrm{~g}$ de ninhidrina, $1,0 \mathrm{~g}$ de $\mathrm{CdCl}_{2}, 80,0 \mathrm{~mL}$ de etanol $80 \%, 10,0 \mathrm{~mL}$ de ácido acético, 20,0 ml de água destilada) e 
incubada por $10 \mathrm{~min}$ a $80^{\circ} \mathrm{C}$ (Matoh et al., 1979). A absorvância foi medida a $506 \mathrm{~nm}$. O branco foi constituído da mistura citada, mas sem a glutamina. Uma curva de calibração foi construída, usando-se glutamato (Glu) como padrão, com concentrações de até $0,3 \mu \mathrm{M}$.

\section{Sintase do glutamato dependente de NADH (NADH-GOGAT; EC 1.4.1.14)}

A atividade da sintase do glutamato dependente de NADH foi quantificada medindo-se o NADH consumido durante a reação:

Glutamina + 2-oxo-glutarato + NADH $\rightarrow$ 2 glutamato $+\mathrm{NAD}^{+}$

O ensaio foi realizado seguindo-se o método proposto por Rhodes et al., (1975), modificado por Tonin (1988) e Junghans e Mosquim (1995), com alíquota de $0,15 \mathrm{~mL}$ do extrato enzimático, glutamina $5,0 \mathrm{mM}$, 2-oxoglutarato $5,0 \mathrm{mM}$, NADH $0,1 \mathrm{mM}$ e tampão TRIS$\mathrm{HCl}$ 50,0 mM (pH 7,5), em volume final de 3,0 $\mathrm{mL}$. O meio de reação foi incubado em banhomaria, a $30^{\circ} \mathrm{C}$, com leituras sendo efetuadas automaticamente a cada 60 segundos, por $5 \mathrm{~min}$, em espectrofotômetro (U-2000, Hitachi), em 340 nm. O branco foi constituído da mistura citada, mas sem a glutamina.

\section{RESULTADOS E DISCUSSÃO}

Observou-se redução significativa nos teores de Pi nas folhas das plantas sob supressão, em relação às do tratamento-controle em todos os estádios do desenvolvimento (Figura 1-A). Resultados similares foram observados na matéria seca da parte aérea em soja (SILVA, 1998), o mesmo ocorrendo com o Pi total em alfafa (Drevon e Hartwing, 1997), Vigna radiata e Vigna aconitifolia (Chaudhary e Fujita, 1998). Os teores de Pi obtidos no presente ensaio podem ser considerados altos, quando comparados com os de plantas de soja submetidas a sete dias de supressão de Pi, que variaram de 0,2 a $0,5 \mathrm{mg} \mathrm{g}^{-1} \mathrm{MF}$ (Silva, 1998). O aumento de Pi nos estádios reprodutivos no tratamento controle deve-se principalmente à remobilização desse elemento a partir das folhas em senescência para as folhas amostradas. Mediante diversos estudos, tem-se demonstrado uma estreita relação entre a remobilização do Pi das folhas em senescência para as regiões em crescimento, quando ocorrem alterações no suprimento de $\mathrm{Pi}$ na época do florescimento (Grabau et al., 1986; Crafts-Brandner, 1992).

Após o ressuprimento, a recuperação desses teores nas folhas nos estádios V3 e V4 (Figura 1-B) é indicativa da capacidade das plantas de absorver Pi, quando esse foi adicionado à solução nutritiva. Entretanto, a ausência de resposta nos estádios R6 e R8 (Figura 1-B) provavelmente ocorreu em razão da queda na absorção e, ou, da maior translocação de Pi das folhas amostradas para as flores e frutos.

Os teores de Pi nas raízes das plantas sob supressão (Figura 1-C) somente mostraram diferenças significativas nos estádios vegetativos em relação às plantas do tratamento-controle.

Com o ressuprimento, os teores de Pi das raízes nos estádios vegetativos não alcançaram valores similares aos do tratamento-controle (Figura 1-D). De modo geral, nos estádios reprodutivos, tanto nas plantas sob supressão bem como nas plantas sob ressuprimento, os teores de Pi nas raízes foram menores em relação aos estádios vegetativos. Esses teores, menores nas raízes em relação aos das folhas nos estádios reprodutivos, podem ser decorrentes da maior remobilização do Pi para a parte aérea (Figura 1-A) e, possivelmente, para as flores e os frutos. Em plantas de feijão sob baixos níveis de $\mathrm{Pi}$, observaram-se redução nos teores de Pi nas raízes, durante os estádios reprodutivos e, aumento desse elemento nas gemas e sementes (Snapp e Lynch, 1996).

Nos nódulos, os teores de Pi nas plantas de alfafa submetidas ao tratamento de supressão diferiram significativamente aos das plantas do tratamento-controle, em todos os estádios analisados (Figura 1-E). Nos estádios vegetativos, esses teores foram mais elevados, tanto nas plantas do tratamentocontrole como nas plantas do tratamento sob supressão, quando comparados com os das plantas de soja submetidas ao mesmo tratamento por um 
período de sete dias (Silva, 1998). O acúmulo de Pi durante os estádios vegetativos é um indicativo de que a remobilização de Pi aumenta durante os estádios reprodutivos, quando o fósforo está em baixa disponibilidade; essa remobilização pode ser um fator importante na produtividade das culturas (Snapp e Lynch, 1996).

Após o ressuprimento, os teores de $\mathrm{Pi}$ alcançaram valores similares aos das plantas do tratamento-controle, exceto em V3 (Figura 1-F).

$\mathrm{O}$ aumento na concentração de $\mathrm{Pi}$ nos nódulos de plantas sob deficiência tem sido atribuído a mecanismos de remobilização e transporte desse elemento de outros órgãos da planta, além da indução na síntese de fosfatases nos bacteróides em nódulos de feijoeiro, o que resultaria em aumento na disponibilidade e na taxa de transporte de Pi (Al-Niemi et al., 1997). A atividade dessas fosfatases nos bacteróides é maior durante os estádios vegetativos, reduzindo-se aproximadamente em $75 \%$ durante os estádios reprodutivos (Al-Niemi et al., 1997). Essas observações podem também ser admitidas para a alfafa e relacionadas com a redução nos teores de Pi nos nódulos em R6 e R8 (Figura 1-E).

Os teores de Pi nos nódulos das plantas de alfafa (Figura 1-E) foram superiores àqueles das raízes em todos os estádios avaliados (Figura 1-C), e, quando comparados aos teores nas folhas (Figura 1-A), somente nos estádios V3 e V4. Dessa forma, pode-se inferir que, em condições subótimas de suprimento de $\mathrm{Pi}$, os nódulos mantêm uma concentração relativamente alta desse elemento. Em plantas de alfafa submetidas a condições limitantes de $\mathrm{Pi}$, os teores de $\mathrm{Pi}$ foram superiores nos nódulos em relação aos das raízes e da parte aérea (Drevon e Hartwing, 1997). Em diferentes cultivares de Vigna aconitifolia, os teores de Pi nos nódulos foram relativamente mais elevados que na parte aérea (Chaudhary e Fujita, 1998).

Os teores de aminoácidos totais nas folhas (Figura 2-A) e nas raízes (Figura 2-C) das plantas sob supressão diferiram significativamente em relação aos das plantas do tratamento-controle, em todos os estádios do desenvolvimento, demonstrando a importância do Pi tanto no processo de fixação do $\mathrm{N}_{2}$ quanto nos processos de assimilação do nitrogênio biologicamente fixado. As leguminosas, quando em simbiose com bactérias fixadoras de $\mathrm{N}_{2}$, são particularmente mais afetadas em seu desenvolvimento em solos com baixa disponibilidade de Pi. Em plantas de soja (Sá e Israel, 1991) e de alfafa (Drevon e Hartwing, 1997) submetidas a baixos níveis de $\mathrm{Pi}$, a atividade da nitrogenase foi significativamente menor que nas plantas do tratamento-controle. As plantas de alfafa (Collins et al., 1986), soja (Israel, 1987) e feijão (Pereira e Bliss, 1987; Araujo et al., 1997) respondem positivamente à fertilização de Pi. A aplicação de fertilizantes fosfatados aumentou a atividade específica da nitrogenase, a concentração do nitrogênio na parte aérea e a matéria seca de plantas de feijão (Al-Niemi et al., 1997).

Os teores de aminoácidos totais nas folhas aumentaram até o estádio V4, tanto nas plantas sob supressão quanto nas plantas do tratamento-controle, reduzindo-se de forma gradual nos estádios R6 e R8 (Figura 2-A). A redução em $\mathrm{R} 6$ e, em maior proporção em $\mathrm{R} 8$, nas folhas, provavelmente está relacionada com a translocação dos aminoácidos na seiva do xilema para os órgãos reprodutivos da planta. A elevada demanda de aminoácidos pelos frutos está relacionada com a biossíntese de proteínas de reserva nas sementes. Em plantas de soja inoculadas, observou-se maior concentração de Naminoacídico, preferencialmente nos frutos (Alves et al., 1994), corroborando a hipótese de que esse órgão desempenha uma forte força de dreno.

Após o ressuprimento, observou-se uma recuperação nos teores de aminoácidos totais nas folhas, nos estádios vegetativos, enquanto nos estádios reprodutivos esses teores mantiveram-se menores do que no tratamento-controle (Figura 2B). A não-recuperação nos teores de aminoácidos totais nas folhas nos estádios reprodutivos pode estar relacionada com a menor síntese, em razão da baixa concentração de $\mathrm{Pi}$ nas folhas e, ou com o maior transporte e acúmulo de aminoácidos para as flores e frutos.

Nas raízes das plantas sob supressão, os teores de aminoácidos foram estatisticamente 


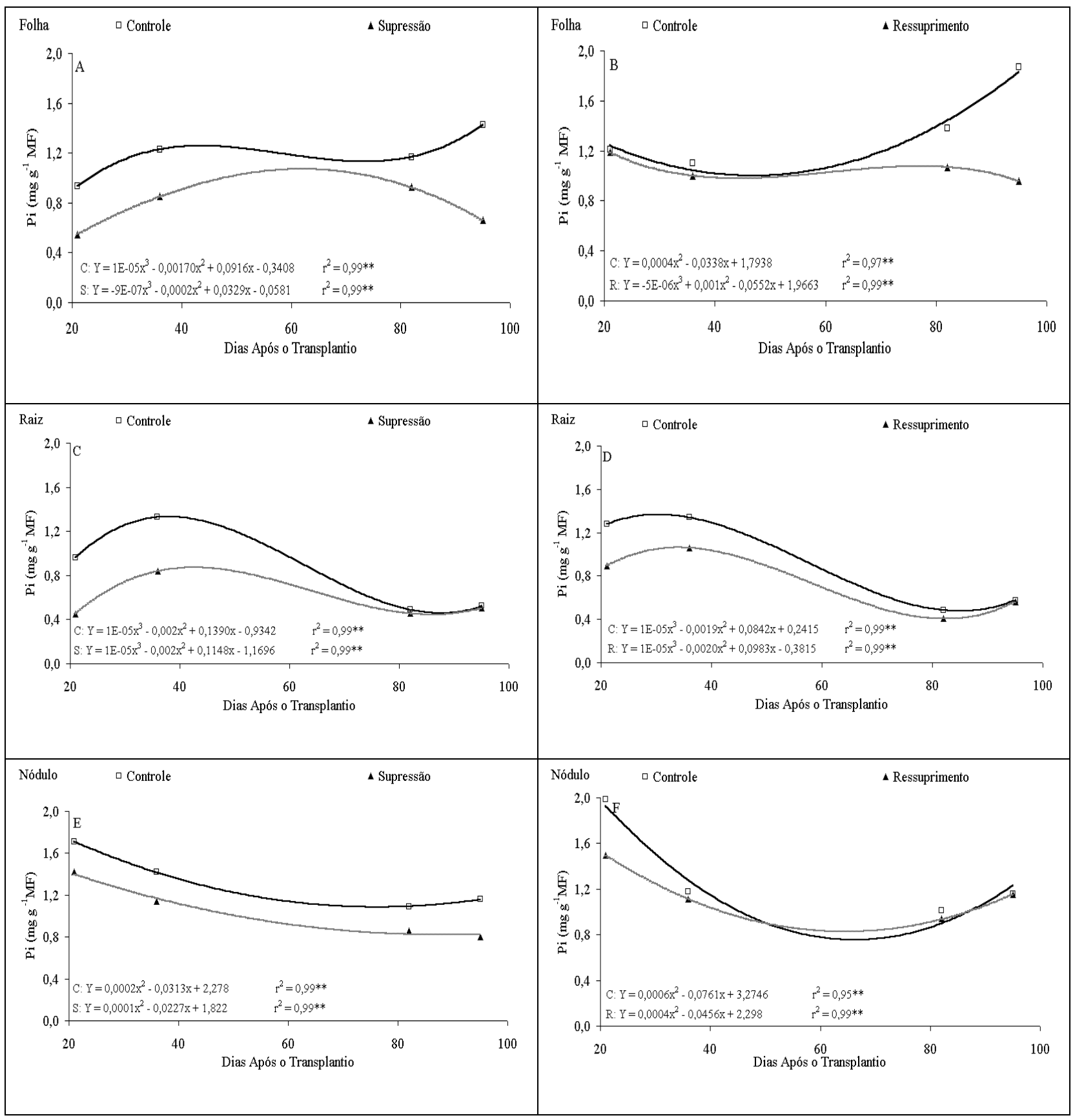

FIGURA 1 - Teores de fosfato inorgâncio (Pi) na matéria fresca (MF) de folhas (A, B) raízes (C, D) e nódulo (E, F) de plantas de alfafa sob supressão e ressuprimento de fosfato, aos 21 (V3), 36 (V4), 82 (R6) e 95 (R8) dias após o transplantio. $\mathrm{C}=$ Controle; $\mathrm{S}=$ Supressão; $\mathrm{R}=$ Ressuprimento. ${ }^{* *}$ Significativo pelo teste $t$ a $1 \%$ de probabilidade. 
diferentes do tratamento-controle e aumentaram dos estádios V3 até R6, diminuindo em R8 (Figura 2-C). Raízes de plantas de feijão sob deficiência de Pi apresentaram uma queda acentuada na fração aminoacídica, quando comparadas às das plantas do tratamento-controle (Ciereszko et al., 1996). Esses aumentos nos teores de aminoácidos totais nas raízes são compatíveis com o estádio de completo florescimento, quando $o$ processo de fixação do $\mathrm{N}_{2}$ se intensifica.

Após o ressuprimento, a recuperação nos teores de aminoácidos totais nas raízes ocorreu em todos os estádios do desenvolvimento (Figura 2-D). Provavelmente, essa recuperação pode estar relacionada com a maior translocação de aminoácidos para esses órgãos.

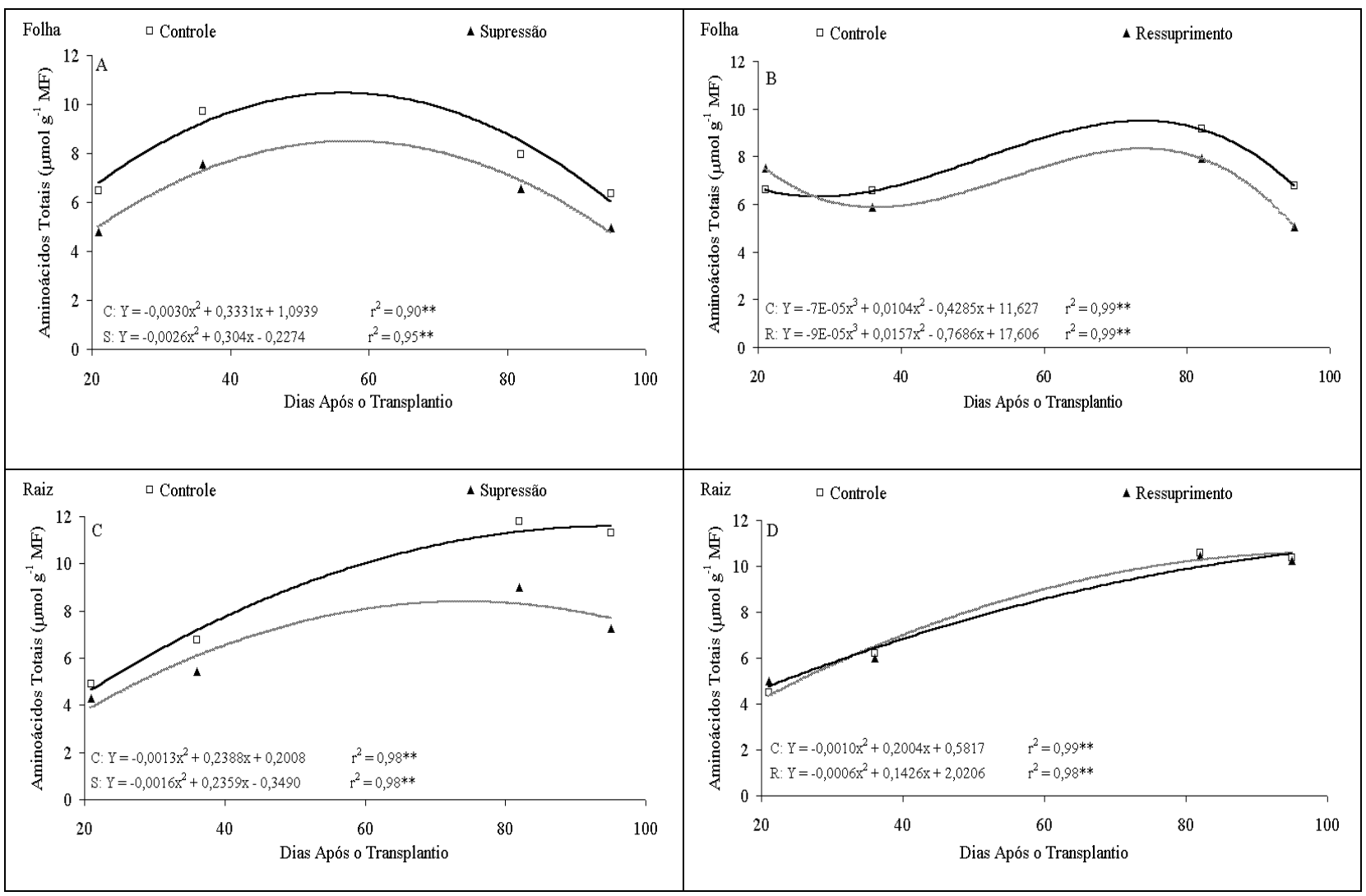

FIGURA 2 - Teores de aminoácidos totais na matéria fresca (MF) de folhas (A, B) e raízes (C, D) de plantas de alfafa sob supressão e ressuprimento de fosfato, aos 21 (V3), 36 (V4), 82 (R6) e 95 (R8) dias após o transplantio. $\mathrm{C}=$ Controle; $\mathrm{S}=$ Supressão; $\mathrm{R}=$ Ressuprimento. $* *$ Significativo pelo teste t a $1 \%$ de probabilidade.

A porcentagem de aminoácidos livres presentes no exsudato do xilema das plantas sob supressão (Tabela 1) e ressuprimento de Pi (Tabela 2) demonstra que a composição pouco variou entre as plantas do tratamento de supressão de Pi e do tratamento-controle em todos os estádios do desenvolvimento.

Observou-se apenas um pequeno aumento na porcentagem de alguns aminoácidos, tais como: glutamato, serina, glicina, arginina e 
alanina durante os estádios reprodutivos. A porcentagem de glutamina decresceu no estádio reprodutivo, tanto nas plantas do tratamentocontrole quanto nas plantas sob supressão de Pi. Essas diferenças demonstram que o estádio do desenvolvimento exerceu maior influência sobre a composição de aminoácidos na seiva do xilema que a supressão de Pi. Geralmente, a composição de aminoácidos na seiva do xilema pode ser alterada em função da fertilização e do estádio do desenvolvimento da planta (Ohtake et al., 1995).
Nas plantas que receberam o ressuprimento de $\mathrm{Pi}$, a porcentagem de glutamina seguiu o mesmo padrão de resposta do ensaio de supressão de $\mathrm{Pi}$, reduzindo-se nos estádios reprodutivos (Tabelas 1 e 2). Essa redução pode estar relacionada à utilização da glutamina na síntese de outros aminoácidos, principalmente asparagina. A asparagina foi o aminoácido encontrado em maior concentração, representando, em média, $50 \%$ em relação aos demais aminoácidos, seguida da glutamina e do aspartato,

TABELA 1 - Composição de aminoácidos livres na seiva do xilema de plantas de alfafa sob supressão de fosfato nos estádios V3, V4, R6 e R8.

\begin{tabular}{|c|c|c|c|c|c|c|c|c|}
\hline & $\mathrm{V} 3 \mathrm{C}$ & V3S & $\mathrm{V} 4 \mathrm{C}$ & V4S & R6C & R6S & R8C & R8S \\
\hline \multicolumn{9}{|c|}{$\mathrm{mol} \%$} \\
\hline Asp & 22,1 & 17,2 & 22,2 & 21,2 & 16,4 & 21,1 & 12,4 & 13,1 \\
\hline Glu & 0,4 & 0,6 & 0,9 & 1,0 & 2,8 & 3,0 & 9,0 & 10,5 \\
\hline Asn & 55,3 & 54,5 & 51,5 & 49,8 & 57,0 & 52,9 & 55,2 & 45,8 \\
\hline Ser & 1,1 & 2,4 & 1,9 & 2,3 & 3,4 & 3,2 & 2,1 & 4,5 \\
\hline Gln & 16,9 & 17,7 & 17,4 & 18,9 & 6,7 & 8,6 & 6,4 & 8,6 \\
\hline Gly & 0,7 & 1,2 & 1,0 & 1,1 & 1,2 & 1,6 & 1,5 & 1,6 \\
\hline Arg & 0,4 & 0,5 & 0,4 & 0,5 & 3,0 & 2,2 & 3,5 & 4,0 \\
\hline Ala & 0,7 & 2,3 & 1,1 & 1,3 & 1,7 & 1,8 & 1,1 & 2,6 \\
\hline Outros & 2,4 & 3,6 & 3,6 & 3,8 & 7,7 & 5,6 & 8,7 & 9,3 \\
\hline
\end{tabular}

$\mathrm{C}=$ Controle; $\mathrm{S}=$ Supressão

TABELA 2 - Composição de aminoácidos livres na seiva do xilema de plantas de alfafa sob ressuprimento de fosfato nos estádios V3, V4, R6 e R8.

\begin{tabular}{ccccccccc}
\hline & V3C & V3R & V4C & V4R & R6C & R6R & R8C & R8R \\
\hline Asp & 13,57 & 17,65 & 17,57 & 22,78 & 12,64 & 16,37 & 12,78 & 13,21 \\
Glu & 0,37 & 0,66 & 1,35 & 1,62 & 5,88 & 6,80 & 7,90 & 8,24 \\
Asn & 54,69 & 58,06 & 49,71 & 51,97 & 51,52 & 53,97 & 46,53 & 49,31 \\
Ser & 2,35 & 1,49 & 1,84 & 3,31 & 2,67 & 3,40 & 3,93 & 3,80 \\
Gln & 23,72 & 18,25 & 20,77 & 10,74 & 11,52 & 6,75 & 8,79 & 5,68 \\
Gly & 0,74 & 0,77 & 0,66 & 2,21 & 1,15 & 1,64 & 1,5 & 1,57 \\
Arg & 0,50 & 0,50 & 0,85 & 1,04 & 4,90 & 3,05 & 6,44 & 3,64 \\
Ala & 1,22 & 0,82 & 0,87 & 0,10 & 1,94 & 1,74 & 2,59 & 1,99 \\
Outros & 2,8 & 1,8 & 6,4 & 6,2 & 7,8 & 6,3 & 9,5 & 12,6 \\
\hline C Con
\end{tabular}

$\mathrm{C}=$ Controle $; \mathrm{R}=$ Ressuprimento 
tanto nas plantas sob supressão quanto nas submetidas ao ressuprimento (Tabelas 1 e 2 ). Resultados similares foram obtidos em plantas de alfafa noduladas, em que os principais compostos nitrogenados encontrados na seiva do xilema foram a asparagina, seguida da glutamina e do aspartato (Maxwell et al., 1984; Ta et al., 1986).

A atividade da GS nos nódulos das plantas sob supressão de Pi foi significativamente menor somente em V3, com decréscimos de $28 \%$ e, em R8, com decréscimos de 7,1\% (Figura 3-A). Com o ressuprimento, a GS, no estádio V3, não recuperou a sua atividade (Figura 3-B). Esse fato sugere que, no inicio de formação dos nódulos, a supressão de Pi comprometeu, de forma mais drástica, o processo de fixação do $\mathrm{N}_{2}$ e a sua posterior assimilação em compostos orgânicos. Provavelmente isso ocorre em razão da taxa reduzida de translocação de carboidratos para os nódulos, ou pela baixa eficiência na utilização de Pi na síntese de ATP.

A atividade da GS, em folhas, mostrou-se muito sensível à supressão de Pi em todos os estádios do desenvolvimento (Figura 3-C). Nos estádios reprodutivos, ocorreu uma redução mais acentuada da atividade, tanto nas plantas do tratamento-controle quanto nas do tratamento sem Pi. A maior atividade da GS nos nódulos (Figura 3A), em relação à GS das folhas (Figura 3-C), durante os estádios reprodutivos em ambos

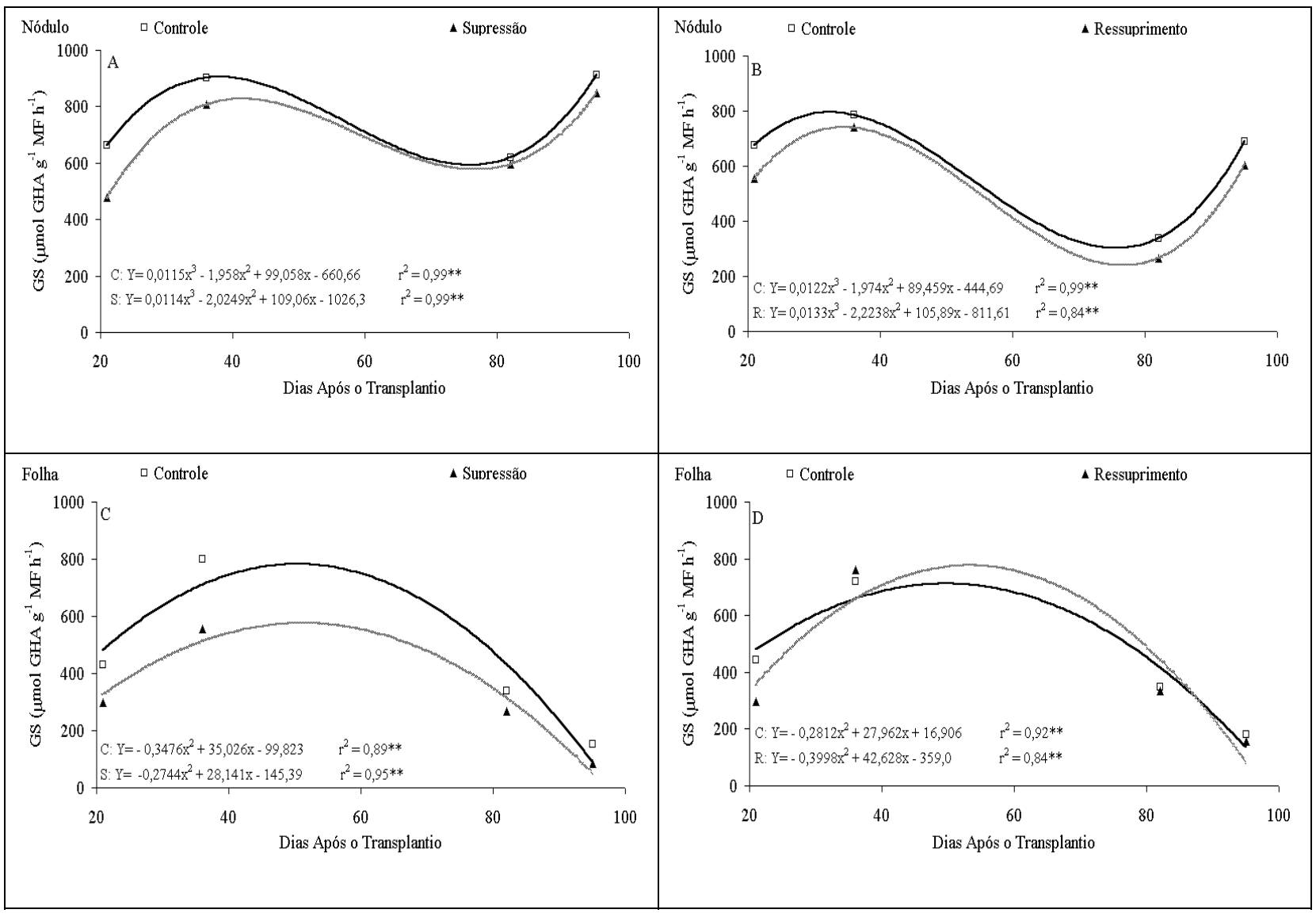

FIGURA 3 - Atividade da sintetase da glutamina (GS) na matéria fresca (MF) de nódulos (A, B) e folhas (C, D) de plantas de alfafa sob supressão e ressuprimento de fosfato, aos 21 (V3), 36 (V4), 82 (R6) e 95 (R8) dias após o transplantio. $\mathrm{C}=$ Controle; $\mathrm{S}=$ Supressão; $\mathrm{R}=$ Ressuprimento. ${ }^{* *}$ Significativo pelo teste $\mathrm{t}$ a $1 \%$ de probabilidade. 
os tratamentos, é um indicativo de que, nesses estádios, a maior parte do nitrogênio biologicamente fixado é incorporada rapidamente em compostos orgânicos nas células nodulares, sendo os produtos dessa assimilação translocados para as flores e frutos.

Após o ressuprimento, observou-se a recuperação da atividade dessa enzima em todos os estádios, exceto em V3 (Figura 3-D).

Nos nódulos das plantas de alfafa, a FdGOGAT mostrou-se muito sensível à supressão de Pi nos estádios V3 e R8, apresentando valores significativamente diferentes aos das plantas do tratamento-controle (Figura 4-A). Os decréscimos na atividade dessa enzima situaram- se em torno de $50 \%$ em V3 e de $59 \%$ em R8 e, com o ressuprimento, não ocorreu a recuperação da atividade (Figura 4-B). A queda na atividade da Fd-GOGAT pode estar diretamente relacionada com o decréscimo da atividade da GS, nos mesmos estádios do desenvolvimento.

A atividade da Fd-GOGAT nas folhas mostrou-se mais sensível à supressão de Pi nos estádios vegetativos, com decréscimos de 39\% em V3 e de $30 \%$ em V4 (Figura 4-C). Com o ressuprimento, a atividade dessa enzima, excetuando-se a das plantas no estádio V3, alcançou valores similares aos das plantas do tratamento-controle (Figura 4-D).

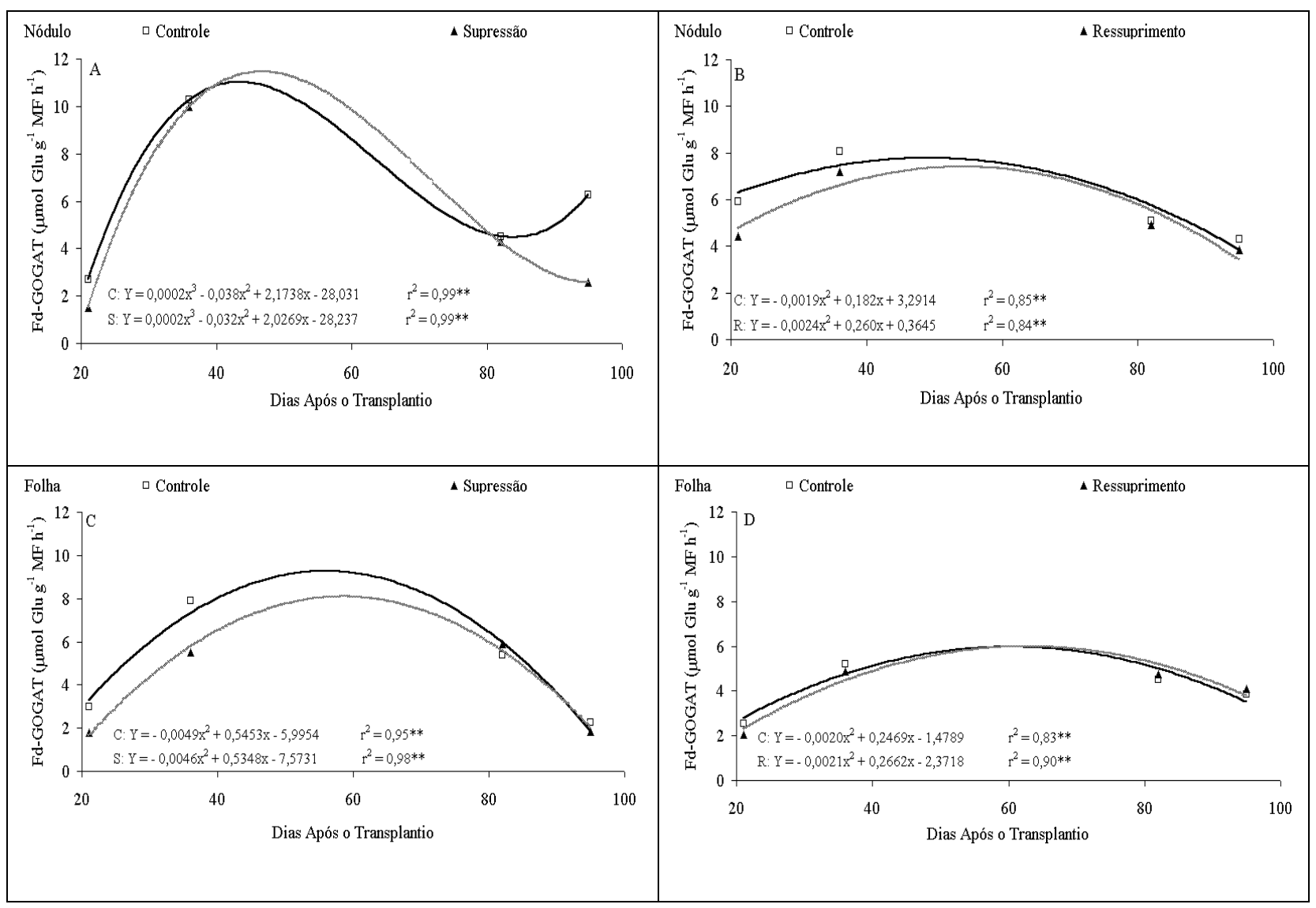

FIGURA 4 - Atividade da sintase do glutamato dependente de ferredoxina (Fd- GOGAT) na matéria fresca (MF) de nódulos (A, B) e folhas $(\mathrm{C}, \mathrm{D})$ de plantas de alfafa sob supressão e ressuprimento de fosfato, aos 21 (V3), 36 (V4), 82 (R6) e 95 (R8) dias após o transplantio. C = Controle; S = Supressão; R $=$ Ressuprimento. ${ }^{* *}$ Significativo pelo teste $\mathrm{t}$ a $1 \%$ de probabilidade. 
Resultados similares foram obtidos em folhas de soja em que a supressão de Pi promoveu uma redução na atividade dessa enzima, tanto no estádio vegetativo quanto no reprodutivo, sendo o período de ressuprimento insuficiente para a recuperação da atividade da Fd-GOGAT (Silva, 1998).

A atividade da NADH-GOGAT nos nódulos das plantas de alfafa sob supressão de Pi foi significativamente menor em relação aos das plantas do tratamento-controle, em todos os estádios do desenvolvimento (Figura 5-A). A enzima mostrou-se muito sensível à deficiência de Pi em todos os estádios. O efeito da supressão de Pi mostrou-se mais drástico, pois não houve recuperação da atividade com o ressuprimento de Pi (Figura 5-B).

$A$ atividade da NADH-GOGAT (Figura 5-C) e a da GS (Figura 3-C), nas folhas, apresentou diferenças significativas quando comparadas à das plantas do tratamentocontrole. A supressão de $\mathrm{Pi}$ foi prejudicial à atividade da NADH-GOGAT, não havendo a recuperação com o ressuprimento (Figura 5-D). A atividade da NADH-GOGAT nos nódulos (Figura 5-A) foi mais elevada que nas folhas (Figura 5-C), o que corrobora os relatos de que, no nódulo, o sistema GS/GOGAT é muito mais eficiente na assimilação do nitrogênio fixado simbioticamente que nas folhas (Ohyama e Kumazawa, 1980).

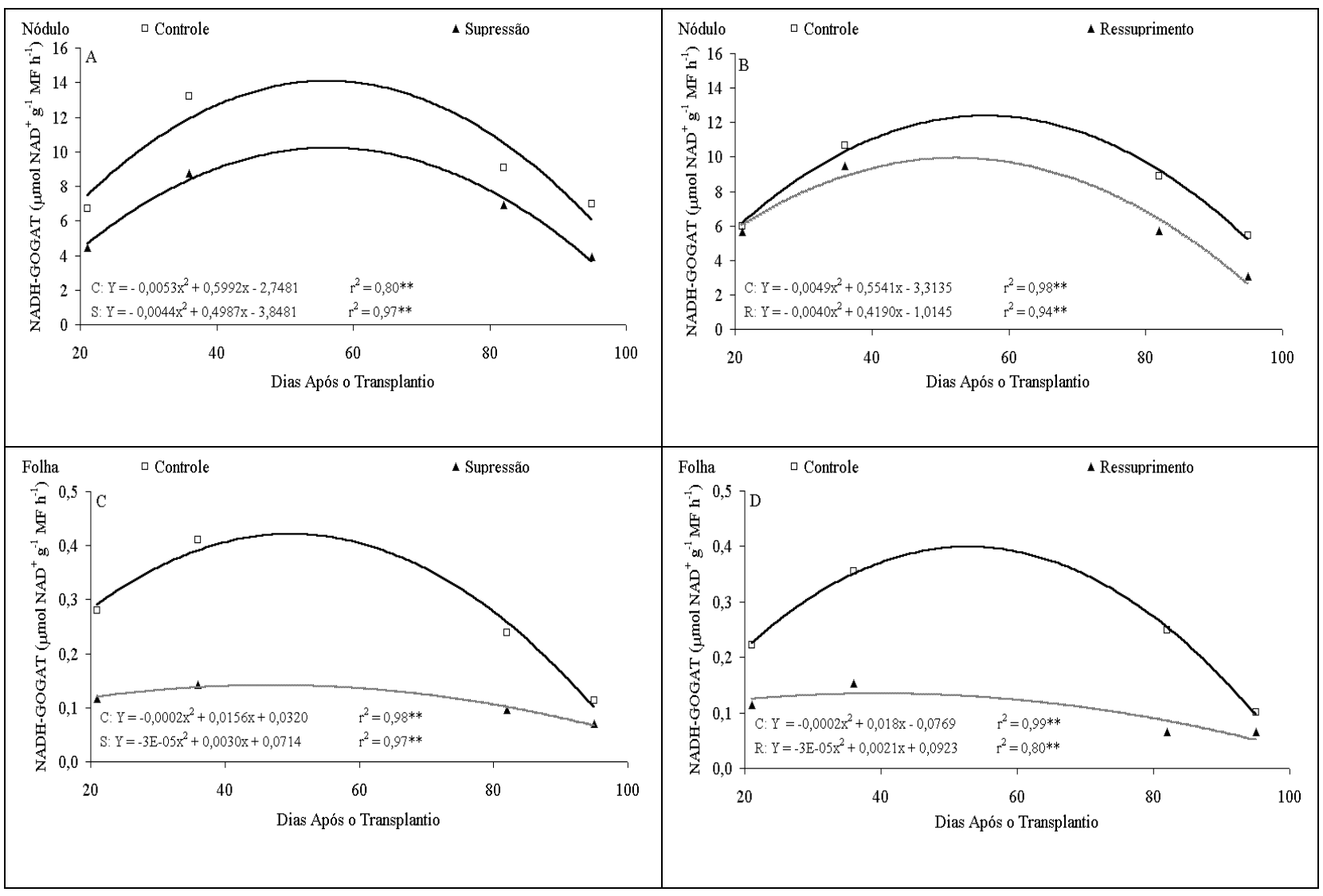

FIGURA 5 - Atividade da sintase do glutamato dependente de NADH (NADH-GOGAT) na matéria fres ca (MF) de nódulos (A, B) e folhas (C, D) de plantas de alfafa sob supressão e ressuprimento de fosfato, aos 21 (V3), 36(V4), 82 (R6) e 95 (R8) dias após o transplantio. $\mathrm{C}=$ Controle; $\mathrm{S}=$ Supressão; $\mathrm{R}=$ Ressuprimento. ${ }^{*}$ Significativo pelo teste t a $1 \%$ de probabilidade. 
O decréscimo nas atividades da GS (Figura 3-C) e de NADH-GOGAT (Figura 5-C) nas folhas durante os estádios reprodutivos está diretamente relacionado com a redução nos teores de aminoácidos totais nas folhas, Figura $2-\mathrm{C}$.

O efeito da supressão de Pi sobre a atividade das enzimas de assimilação do nitrogênio nos nódulos das plantas de alfafa, nos diferentes estádios do desenvolvimento, não se relacionou diretamente com a composição de aminoácidos na seiva do xilema. A ausência de resposta significativa em relação à composição de aminoácidos nas plantas sob supressão de Pi pode estar mais relacionada com a atividade das enzimas que participam do processo de síntese e degradação dos diversos aminoácidos presentes nas plantas.

\section{REFERÊNCIAS BIBLIOGRÁFICAS}

AL-NIEMI, T.S.; KAHN, M.L. AND McDERMOTT, T.R. P Metabolism in the bean-Rhizobium tropici symbiosis. Plant Physiology, 113:1233-1242, 1997.

ALVES, R.B.N.; SANT'ANNA, R.; CAMBRAIA, J. E BORGES, A.C. Composição do $\mathrm{N}$ solúvel total de plantas de soja durante o estádio reprodutivo. Revista Brasileira de Fisiologia Vegetal, 6:47-52, 1994.

ANDERSON, M. P., VANCE, C. P., HEICHEL, G. H., MILLER, S. S. Purification and characterization of NADH-glutamate synthase from alfalfa root nodules. Plant Physiology, 90:351-358, 1989.

ARAUJO, A.P.; TEIXEIRA, M.G. AND ALMEIDA, D.L. Phosphorus efficiency of wild and cultivated genotypes of common bean (Phaseolus vulgaris L.) under biological nitrogen fixation. Soil Biology and Biochemistry, 29:951-957, 1997.
BENNY, A. G., BOLAND, M. J. Enzymes of nitrogen metabolism in legume nodules. Purification and properties of NADHdependent glutamate synthase from lupin nodules. European Journal Biochemistry, 79:355-362, 1977.

BENSON, J.R. AND HARE, P.E. Ophthalaldehyde fluorogenic detection of primary amines in the picomole range. Comparison with fluorescamine and ninhydrin. Proceedings of the National Academy of Sciences, USA, 72:619-629, 1975.

CHAUDHARY, M.I. AND FUJITA, K. Comparison of phosphorus deficiency effects on the growth parameters of mashbean, mungbean, and soybean. Soil Science Plant Nutrition, 44: 19-30, 1998.

CHEN, F. L., CULlimORE, J. V. Two isoenzymes of NADH-dependent glutamate synthase in root nodules of Phaseolus vulgaris L. : Purification, properties and changes during development. Plant Physiology, 88:1411-1417, 1988.

CIERESZKO, I.; GNIAZDOWSKA, A.; MIKULSKA, M. AND RYCHTER, A.M. Assimilate translocation in bean plants (Phaseolus vulgaris L.) during phosphate deficiency. Journal Plant Physiology, 149:343-348, 1996.

COLLINS, M.; LANG, D.J. AND KELLING, K.A. Effects of phosphorus, potassium, and sulfur on alfalfa nitrogen-fixation under field conditions. Agronomy Journal, 78:959963, 1986.

CRAFTS-BRANDNER, S.J. Significance of leaf phosphorus remobilization in yield production in soybean. Crop Science, 32:420-424, 1992.

DREVON, J.J. AND HARTWING, V.A. Phosphorus deficiency increases the argoninduced decline of nodule nitrogenase activity in soybean and alfalfa. Planta, 201:463-469, 1997. 
GABAU, L.J.; BLEVINS, D.G. AND MINOR, H.C.P. Nutrition during seed development. Leaf senescence, pod retention, and seed weight of soybean. Plant Physiology, 82:1008-1012, 1986.

HAUSLER, R. E., BLACKWELL, R. D., LEA, P. J., LEEGOOD, R. C. Control of photosynthesis in barley leaves with reduced activities of glutamine synthetase or glutamate synthase. I. Plant characteristics and changes in nitrate, ammonium and amino acids. Planta, 194(3):406-417, 1994.

HOAGLAND, D.R. AND ARNON, D.I. The water culture method for growing plants without soil. California Agricutural Experimental Station Circular, 347:1-32, 1950.

HOUGE, E.; WILCOX, G.E. AND CANTLIFFE, D.J. Effect of soil phosphorus level on phosphate fractions in tomato leaves. Journal of Horticultural Science, 95:174-176, 1970.

ISRAEL, D.W. Investigation of the role of phosphorus in symbiotic dinitrogen fixation. Plant Physiology, 84:835-840, 1987.

JARRET, H.W.; COOKSY, K.D. AND ELLIS, B. The separation of o-phthalaldehyde derivatives of amino acids by reversed-phase chromatography on octylsilica colum. Analytical Biochemistry, 153:189-198, 1986.

JUNGHANS, T. G., MOSQUIM, P. R. Atividade da sintetase da glutamina e sintase do glutamato em explantes de frutos de soja sob diferentes fontes de nitrogênio. Revista Brasileira Brasileira FisiologiaVegetal, 7(1):67-74, 1995.

LAM, H. M., COSCHIGANO, K. T., OLIVEIRA, I. C. The molecular-genetics of nitrogen assimilation into amino acids in higher plants. Annual Review of Plant Physiology and Plant Molecular Biology, 47:569-593, 1996.
MARSCHNER, H. Mineral nutrition of higher plants. 2 ed. London: Academic Press, 1995, $889 \mathrm{p}$.

MATOH, T., SUZUKI, F., IDA, S. Corn leaf glutamate synthase: Purification and properties of the enzyme. Plant Cell and Physiology, 20(7):1329-1340, 1979.

MAXWELL, C.A.; VANCE, C.P.; HEICHEL, G.H. AND STADE, S. $\mathrm{CO}_{2}$ fixation in alfalfa and birdsfoot trefoil root nodules and partitioning of ${ }^{14} \mathrm{C}$ to the plant. Crop Science, 24:257-264, 1984.

OHTAKE, N.; NISHIWAKI, T. AND MIZUKOSHI, K. Amino acid composition in xylem sap of soybean related to the evaluation of $\mathrm{N}_{2}$ fixation by the relative ureide method. Soil Science Plant Nutrition, 41:95-102, 1995.

PEREIRA, P.A.A. AND BLISS, F.A. Nitrogen fixation and plant growth of common bean (Phaseolus vulgaris L.) at different level of phosphorus availability. Plant and Soil, 104:7984, 1987.

QIU, J. AND ISRAEL D.W. Diurnal starch accumulation and utilization in phosphorusdeficient soybean plant. Plant Physiology, 98:316-323, 1992.

RENA, A.B. E MASCIOTTI, Z. Efeito do déficit hídrico sobre o metabolismo do nitrogênio e o crescimento de quatro cultivares de feijão (Phaseolus vulgaris L.). Revista Ceres, 23:288-301, 1976.

RIBET, J. AND DREVON, J.J. Phosphorus deficiency increases the acetylene-induced decline in nitrogenase activity in soybean (Glycine $\max$ (L.) Merr.). Journal Experimental of Botany, 46 : 1479-1486, 1995.

RHODES, D., RENDON, G. A., STEWART, G. $\mathrm{R}$. The control of glutamine synthetase level in Lemna minor (L). Planta, 125(3):201$211,1975$. 
SÁ, T. M., ISRAEL, D. W. Energy status and functioning of phosphorus-deficient soybean nodules. Plant Physiology, 97:928-935, 1991.

SÁ, T.M. AND ISRAEL, D.W. Nitrogen assimilation in nitrogen-fixing soybean plants during phosphorus deficiency. Crop Science, 35:814-820, 1995.

SAS INSTITUTE INCORPORATION. The SAS-System for Windows release 6.11 (software). Cary, North Caolina:SAS Institute Incorporation, 1996.

SILVA, D.M. Crescimento, fotossíntese e metabolismo do nitrogênio em plantas de soja noduladas sob omissão e ressuprimento de fósforo. Viçosa, MG, Universidade Federal de Viçosa. 117p. Tese de Doutorado, 1998.

SNAPP, S.S. AND LYNCH, J.P. Phosphorus distribution and remobilization in bean plants as influenced by phosphorus nutrition. Crop Science, 36:929-935, 1996.

SUZUKI, A., VIDAL, J., NGUYEN, J., GADAL, P. Occurrence of ferredoxindependent glutamate synthase in plant cell fraction of soybean root nodules (Glycine max). FEBS Letters, v. 173, n. 1, p. 204208, 1984.

TA, T. C., FARIS, M. A., MACDOWALL, F. D. H. Pathways of nitrogen metabolism in nodules of alfalfa (Medicago sativa L.) Plant Physiology, 80:1002-1005, 1986.

TONIN, G. S. Influência da fonte de nitrogênio na atividade de enzimas envolvidas no processo de assimilação de amidas e ureídeos em cotilédones imaturos de soja mantidos em cultura. Campinas, SP, Universidade Estadual de Campinas, 149p., Tese de Doutorado, 1988.

TWARY, S.N. AND HEICHEL, G.H. Carbon cost of dinitrogen fixation associated with dry matter accumulation in alfalfa. Crop Science, 31:985-992, 1991.

VANCE, C.P.; HEICHEL, G.H.; BARNES, D.K.; BRYAN, J.W. AND JOHNSON, L.E. Nitrogen fixation, nodule development and vegetative regrowth of alfalfa (Medicago sativa L.) following harvest. Plant Physiology, 64:1-8, 1979.

VINCENT, J.M. A manual for the practical study of the root-nodule bacteria. London: Blackwell Scientific, 1970. 164p. (IPB Handbook, $\mathrm{n}^{\mathrm{o}}$ 15). 